\title{
On Wage Policies and Unemployment
}

\author{
Andreas Irmen
}

University of Heidelberg, CEPR, London, and CESifo, Munich

\begin{abstract}
In economies where the price of labour is determined outside of competitive markets the question arises as to whether the observed evolution of wages is likely to contribute to a decline in unemployment. I develop and discuss a benchmark, the neutral wage policy, to which the actual evolution of wages can be compared. Here, neutrality refers to the unemployment rate and not to the level of employment. If the actual wage growth falls short of this benchmark then the evolution of wages is said to have contributed to a decline in the unemployment rate. This benchmark is based on fairly general assumptions on the aggregate production technology, incorporates changes in the supply of labour, and accounts for changes in the competitive environment of firms. Finally, I discuss the relation to the benchmark of the German Council of Economic Experts [1].
\end{abstract}

Keywords: Productivity growth, wages, employment.

\section{INTRODUCTION}

In many economies the price of labour is determined outside of competitive markets. Negotiations between unions and employers' associations are a case in point. In these economies the question arises as to how an assessment of the results of such negotiations should be made. The present paper develops a measuring rod against which the observed evolution of real wages can be assessed in view of its implications for the evolution of the level of employment and the unemployment rate.

There are at least two related observations as to why assessments of the kind presented here matter. First, in order to legitimate their stances both negotiating parties pretend to act in the public interest. Workers' purchasing power and the cost-of-labor argument put forward by unions and employers do not only benefit their respective interest groups. They are also meant to be in the public interest since they raise the level of employment. The difficult challenge is then to ask who is right. Second, the institutional framework for wage negotiations affects the bargaining power of both parties and has, therefore, an important impact on the resulting wage. If an appropriate benchmark indicated that the negotiated wage failed to be in the public interest then the political system is likely to intervene and to change this framework. For instance, if wages were considered to be too high it is likely that changes in the institutional framework would strengthen the employers' position.

I refer to the benchmark developed here as the neutral wage policy, i.e., if the actual evolution of the real wage coincides with the evolution prescribed by this benchmark, then the unemployment rate remains constant; if it falls short of it, the unemployment rate declines. This concept incorporates the following features of the aggregate demand

*Address correspondence to this author at the University of Heidelberg, Faculty of Economics and Social Studies, Grabengasse 14, D-69117 Heidelberg, Germany; E-mail: airmen@uni-hd.de. and the aggregate supply of labour. First, it is based on fairly general assumptions on the aggregate production technology. Second, it considers net inflows into and net outflows out of the labour market. Third, it accounts for changes in the competitive environment in which firms operate. Here, I follow [2] who argue forcefully that the interaction between product and labour markets is essential for an understanding of the (European) unemployment problem.

The difference between the neutral wage policy and the actual evolution of the real wage gives rise to the notion of wage moderation. I show that this notion can be used to quantify the time necessary to, say, halve the unemployment rate. In my calibrations, wage moderation turns out to be a powerful means to attack the unemployment problem.

Finally, I compare the neutral wage policy to the concept of the employment-neutral wage policy enunciated by the German Council of Economic Experts, henceforth GCEE [1]. I show that the rule used by the GCEE coincides with the more general neutral wage policy only if both the labour supply and the competitive environment do not change over time, and if the elasticity of substitution is equal to unity.

The literature on wage policies und employment starts from the benchmark according to which real wage growth in line with labour productivity growth leaves the level of employment unaffected. This rule is readily derived in a static framework (e.g., [3] for a textbook treatment). However, in a dynamic context, this rule may induce socalled "decay results" with ever declining levels of employment (see, $[4,5]$ ). Moreover, there is a vast literature concerned with the effects of minimum wages on employment and other important economic variables. Recent examples include [6,7], where the former focuses on pensions and the latter on the direction of technical change. Quite typically, these studies do not address the question as to how wages ought to evolve to reduce the unemployment rate or to re-establish full employment. The purpose of the present paper is to provide a first step in this direction. 
The paper is organized as follows. Section II sets out the model. Section III studies the relationship between the evolution of the level of employment and the real wage. Section IV develops the concept of the neutral wage policy. Section $\mathrm{V}$ has the comparison to the GCEE's recommendation. Section VI concludes.

\section{THE MODEL}

Consider a closed economy with a household sector, a production sector, and an active government. The production sector comprises a competitive final-good sector and an intermediate-good sector producing differentiated goods that serve as inputs in the production of the final good. The final good can be either consumed or invested. If invested it serves as capital in the production of the intermediate good. Time is continuous. To simplify the notation the time argument is often suppressed.

I follow the usual practice and assume constant returns to scale (CRS) at the level of final-good and intermediate-good production. This assumption would simplify the integration of the present setup into a full-fledged intertemporal general equilibrium model since pure profit incomes are absent. However, given that the derivation of the neutral wage policy is based on first-order conditions, deviations from CRS that do not affect the sufficiency of these conditions for profit-maximization do not affect any qualitative result.

The Household Sector Identical households are represented by the unit interval. At $t$, each household has $N(t)$ members endowed with one unit of labour. This unit is inelastically supplied to the labour market. Then, $g_{N}(t) \equiv \dot{N}(t) / N(t)$ is the growth rate of labour supply at t and

$N(t)=\exp \left[\int_{0}^{t} \mathrm{~g}_{\mathrm{N}}(v) d v\right]$

with $N(0)=N_{0}=1$ as initial value. Households own the economy's capital stock and rent it to the production sector.

Government The government charges a value added tax at rate $\tau_{g}$ to finance its real consumption, $G$. Moreover, it runs an unemployment insurance to which both firms and households contribute. Denote $\tau_{f}, \tau_{w} \in(0,1)$ the firms' and the worker's contribution rates, respectively. The unemployment insurance pays an unemployment benefit $b w$, where $b \in(0,1)$ and $w$ is the gross wage per unit of employed labour. A balanced budget requires $w\left(\tau_{f}+\tau_{w}\right) L=(N-L) \quad b w$ where $L$ is the level of employment. Then, given $b$ the contribution rates are linked to the unemployment rate, $u \equiv 1-L / N$, by

$$
\tau_{w}+\tau_{f}=b \frac{u}{1-u} .
$$

The Final-Good Sector Many competitive firms produce a single homogeneous final good using the quantities $x(j), j \in[0, J]$, of all available differentiated intermediates $J>0$. Production occurs under constant returns to scale. Therefore, we can study the final-good sector through the lens of a single representative firm.

Let

$Y=\left[J^{-\frac{\mu-1}{\mu}} \int_{0}^{J} x(j)^{\frac{1}{\mu}} d j\right]^{\mu}$

be the production function of the final-good output $Y$. The parameter $\mu>1$ is the mark up factor charged by intermediate-good firms and determines the elasticity of substitution between intermediates, $\mu /(\mu-1)$. Due to the term in front of the integral there are no gains from specialization associated with a rise in $J$.

Denote $p_{Y}$ and $p(j)$ the money prices net of value-added tax (VAT) of one unit of the final good and one unit of the intermediate good $j$, respectively. Then, the cash flow is

$\left(1+\tau_{g}\right)\left(p_{Y} Y-\int_{0}^{J} p(j) x(j) d j\right)$

where the term in parenthesis is the firm's nominal profit. Maximizing the latter subject to (3) gives rise to a continuum of conditional factor demands

$x(j)=\frac{Y}{J}\left(\frac{p(j)}{P}\right)^{-\frac{\mu}{\mu-1}}$ for all $j \in[0, J]$,

where

$P \equiv\left[\frac{1}{J}\left(\int_{0}^{J} p\left(j^{\prime}\right)^{-\frac{1}{\mu-1}} d j^{\prime}\right)\right]^{-(\mu-1)}$

is the minimum cost of one unit of $Y$ net of VAT.

The Intermediate-Good Sector All $J$ intermediate-good firms produce one good and have access to the same neoclassical production function with the usual properties (e.g., [8]).

$x(j)=F(K(j), A L(j))=A L(j) f(k(j))$,

where $K(j)$ and $L(j)$ denote the employed levels of capital and labor at firm $j, A$ represents the level of laboraugmenting technological knowledge available to all firms, $k(j) \equiv K(j) / A L(j)$, and $f(k(j)) \equiv F(k(j), 1)$. Firms take the rental rate of capital, $R$, the cost of labour, $w\left(1+\tau_{f}\right)$, and the value-added tax rate, $\tau_{g}$, as given and choose the plan $(p(j), x(j), L(j), K(j))$ that maximizes turnover minus factor costs

$p(j) x(j)-w\left(1+\tau_{f}\right) L(j)-r K(j)$

subject to (5) and (7).

Intuitively, the optimal plan involves conditions for both input markets and the output market. Cost minimization requires

$c(j)=\frac{w\left(1+\tau_{f}\right)}{A\left[f(k(j))-k(j) f^{\prime}(k(j))\right]}=\frac{R}{f^{\prime}(k(j))}$, 
where $c(j)$ is unit and marginal cost. The demand (5) implies a constant markup over marginal cost, i.e.,

$$
p(j)=\mu c(j)
$$

Since all intermediate-good firms possess the same constant-returns-to-scale technology and face the same factor prices, (8) implies $k(j)=k$ and $c(j)=c$. Thus, with (9), $p(j)$ $=p=\mu c$.

\section{THE EVOLUTION OF EMPLOYMENT AND THE REAL WAGE}

Constant returns to scale in final good production and (6) imply that the equilibrium should have $p_{Y}=P=p$. We normalize such that all prices are expressed in units of consumables, i.e., $p_{Y}\left(1+\tau_{g}\right)=1$. Then, using (9) in (8), we obtain the conditions that relate the capital intensity to factor prices

$\frac{A}{\mu\left(1+\tau_{g}\right)}\left[f(k)-k f^{\prime}(k)\right]=w\left(1+\tau_{f}\right)$

$\frac{1}{\mu\left(1+\tau_{g}\right)} f^{\prime}(k)=R$

We assume that the market for capital is competitive such that $R$ adjusts to $k$ and the available capital stock, $K(t)$, is employed. However, there is unemployment of the labor force, i.e., $w(t)$ exceeds the laissez-faire level and $L(t)<N(t)$. Based on (10) we obtain the following prediction about the evolution of the level of employment over time. Let $g_{z} \equiv \dot{z}(t) / z(t)$ be the growth rate of variable $z$.

Proposition 1 Denote the elasticity of substitution between capital and efficient labor and the output elasticity of capital at $t$ by

$\sigma(t) \equiv-\frac{f^{\prime}\left(f-k(t) f^{\prime}\right)}{k(t) f^{\prime \prime} f}>0$ and $\alpha(t) \equiv-\frac{f^{\prime} k(t)}{f}>0$

where the argument of $f$ is $k(t)$. Then, the evolution of the economy's level of employment satisfies

$g_{L}(t)=\left[g_{K}(t)-g_{A}(t)\right]-\left[g_{w}(t)-g_{A}(t)\right] \frac{\sigma(t)}{\alpha(t)}-\left[d \tau+g_{\mu}(t)\right] \frac{\sigma(t)}{\alpha(t)}$,

where

$d t \equiv g_{\tau_{g}}(t) \frac{\tau_{g}(t)}{1+\tau_{g}(t)}+g_{\tau_{f}}(t) \frac{\tau_{f}(t)}{1+\tau_{f}(t)}$.

Proof Differentiate (10) with respect to time, take growth rates, and use the definitions of $k(t), \sigma(t)$, and $\alpha(t)$.

Equation (13) of Proposition 1 identifies three channels that impinge on the evolution of the level of employment at $t$. First, there is the contribution of capital accumulation. For given growth rates $g_{z}(t), z=w, \tau_{g}, \tau_{f}, \mu$, capital accumulation contributes to a rise in the level of employment only if capital per efficiency unit increases over time, i.e., more jobs are created with new capital than saved through technical change.

Second, there is the effect induced by a change in the real wage per efficiency unit. The strength of this effect on employment depends on how the technological variables $\sigma$ and $\alpha$ relate to each other. Intuitively, these variables capture the substitution and the scale effect associated with a change in $w$.

Third, there is the effect induced by changes in the competitive environment. A rise in $\tau_{g}$ or $\mu$ reduces the value marginal product of labour, and, ceteris paribus, the level of employment declines. A rise in $\tau_{f}$ increases the marginal costs of labour. From the first-order condition (10) it is obvious that the effect on employment works through an adjustment of $k$. Therefore, the strength of this channel is determined by the technology represented by the fraction $\sigma$ / $\alpha$. $^{1}$

\section{WAGE POLICY AND UNEMPLOYMENT}

The definition of the unemployment rate delivers $g_{u}(t)=$ $(1 / u(t)-1)\left(g_{N}(t)-g_{L}(t)\right)$. Hence, for the evolution of the unemployment rate, one needs to account for the evolution of the supply of labour represented by $g_{N}(t)$. With Proposition 1 we have

$g_{u}(t)=\left(\frac{1}{u(t)}-1\right)\left(\begin{array}{l}g_{N}(t)-\left[g_{K}(t)-g_{A}(t)\right]+ \\ +\left[g_{w}(t)-g_{A}(t)+d \tau+g_{\mu}(t)\right] \frac{\sigma(t)}{\alpha(t)}\end{array}\right)$.

Hence, $g_{u}(t)$ is proportionate to $g_{w}(t)$. Moreover, there is a critical growth rate of the real wage such that $g_{u}(t)=0$. We refer to this growth rate as the neutral wage policy, denoted by $g_{w}^{P}(t)$. Whenever the actual wage growth, $g_{w}(t)$, remains below $g_{w}^{P}(t)$, the unemployment rate falls.

Proposition 2 An actual evolution of the real wage that satisfies

$$
\begin{aligned}
& g_{w}(t)<g_{w}^{P}(t) \equiv g_{A}(t)-\left[d \tau+g_{\mu}(t)\right]+ \\
& +\left[g_{K}(t)-g_{A}(t)-g_{N}(t)\right] \frac{\alpha(t)}{\sigma(t)}
\end{aligned}
$$

implies a decline in the unemployment rate at $t$, i.e., $g_{u}(t)<$ 0 .

Proof By definition, $g_{w}^{P}(t)$ is the level of $g_{w}(t)$ such that the second term in parentheses on the right-hand side of (15) is zero. Since the first term in parentheses on the right-hand side of (15) is strictly positive, Proposition 2 follows.

Hence, the growth rate of the real wage that leaves the unemployment rate unaffected, $g_{w}^{P}(t)$, depends on changes on the supply and the demand side. The first determinant is the growth rate of labor-saving technical change $\mathrm{g}_{A}(\mathrm{t})$. It would be the only determinant in a steady state where, by definition, the two other terms in brackets on the right-hand side of (16) vanish. The second term picks up the effect of

\footnotetext{
${ }^{1}$ This latter fraction is certainly hard to measure, in particular, due to the uncertainty surrounding the appropriate value for $\sigma$. Intuitively, the elasticity of substitution is likely be smaller than one in the short run and greater than one in the long run [2]. Moreover, it is likely to be higher in an economy engaged in international trade in goods à la Heckscher-Ohlin (see, [9] and [10]). See, e. g., [11] for a comprehensive list of estimates of the elasticity of substitution.
} 
changes in the competitive environment of firms. As discussed in the context of the profit-maximizing condition (10), a hike in the consumption tax, an increasing monopoly power, or a rise in the firm's contribution rate to the unemployment insurance reduce employment. Accordingly, these changes reduce $g_{w}^{P}(t)$. The second term in brackets captures the role of capital accumulation. Intuitively, $g_{w}^{P}(t)$ is greater if more new jobs are created than destroyed through technical change and needed to accommodate a rising labor supply, i.e., when $g_{K}(t)>g_{A}(t)+g_{N}(t)$.

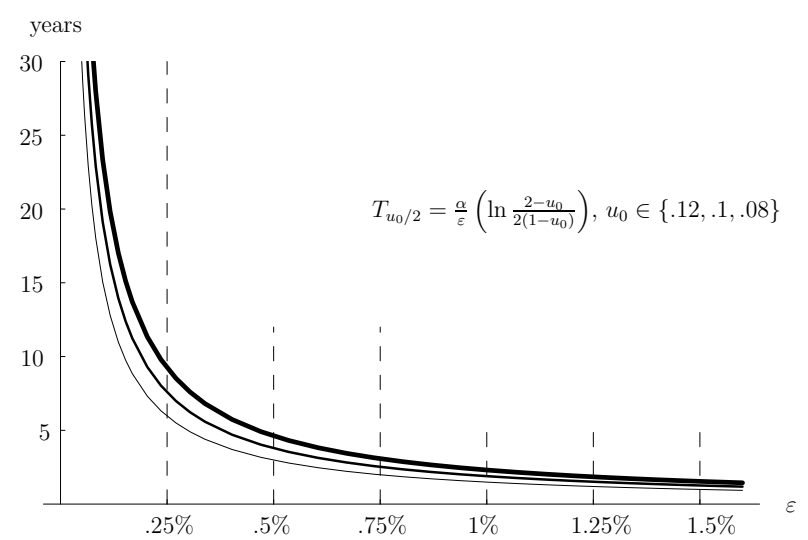

Fig. (1). Years to halve the unemployment rate.

Proposition 2 suggests a natural way to measure wage moderation. We refer to the parameter $\varepsilon(t)$,

$\varepsilon(t) \equiv g_{w}^{P}(t)-g_{w}(t)$,

as the degree of wage moderation at t. If $\varepsilon(t)>0$, then the evolution of wages has a positive effect on the decline of the unemployment rate.

To evaluate the role of wage moderation suppose that wages evolve according to $g_{w}(t) \equiv g_{w}^{P}(t)-\varepsilon(t)$. Using the latter and Proposition 1 we find that $g_{L}(t)=g_{N}(t)+\varepsilon(t) \sigma(t) / \alpha(t)$. To simplify, suppose that the aggregate production function is Cobb-Douglas such that $\sigma(t)$ $=1$ and $\alpha(t)=\alpha$. Moreover, admit that the degree of wage moderation remains constant over time, i.e., $\varepsilon(t)=\varepsilon$. Then, the evolution of the unemployment rate is given by

$u(t)=1-\lambda_{0} e^{\frac{\varepsilon}{\alpha} t}$

where $\lambda_{0}=L_{0} / N_{0} \in(0,1)$ determines the initial value of the unemployment rate, $u_{0}=1-\lambda_{0}$. We can use (18) to compute the finite time span, $T_{\bar{u}}$, necessary to reduce the unemployment rate to any level $\bar{u} \in\left[0, u_{0}\right]$. This gives

$T_{\bar{u}}=\frac{\alpha}{\varepsilon} \ln \left(\frac{1-\bar{u}}{1-u_{0}}\right)$.

The time span $T_{\bar{u}}$ decreases in the degree of wage moderation, $\varepsilon$, since a lower wage growth leads firms to lower the capital intensity through additional hiring. This tendency is weaker if the output elasticity of capital is high (see Proposition 1). Accordingly, $T_{\bar{u}}$ increases in $\alpha$. Quite intuitively, the time span $T_{\bar{u}}$ is longer the higher the initial level of unemployment and the lower the desired unemployment rate $\bar{u}$.

Fig. (1) depicts the time to halve the unemployment rate, $T_{u_{0} / 2}$, as a function of $\varepsilon$ for $\alpha=.35$ and initial unemployment rates $u_{0} \in\{.12, .1, .08\}^{2}$. The thickest line corresponds to $\mathrm{u}_{0}=$ .12 , the thinnest to $\mathrm{u}_{0}=.08$. The striking feature is the high sensitivity of $T_{u_{0} / 2}$ for small degrees of wage moderation. For instance, when $\mathrm{u}_{0}=.12$ we find that a rise in wage moderation from $\varepsilon=.1 \%$ to $\varepsilon=.25 \%$ reduces the time to halve from $T_{.12 / 2}(\varepsilon=.1 \%)=23$ to $T_{.12 / 2}(\varepsilon=.25 \%)=7.7$ years. This suggests that wage moderation can be a powerful means to attack the unemployment problem.

These results have important repercussions for the contribution rates to the unemployment insurance that satisfy (2). To see this, suppose that $b$ is time-invariant and that $\tau_{w}$ $=\tau_{f}$. Then, we have

$$
\tau_{f, u_{0}}=\left(\frac{b}{2}\right)\left(\frac{u_{0}}{1-u_{0}}\right) \text { and } \tau_{f, \frac{u_{0}}{2}}=\left(\frac{b}{2}\right)\left(\frac{u_{0}}{2-u_{0}}\right)
$$

or

$$
\tau_{f, \frac{u_{0}}{2}}=\left(\frac{1-u_{0}}{2-u_{0}}\right) \tau_{f, u_{0}}
$$

For instance, if $u_{0} \in[.12, .08]$, we obtain that the contribution rate drops to about $48 \%$ of its initial level when the unemployment rate is cut in half. Clearly, the degree of wage moderation determines how long it takes to accomplish such a reduction.

\section{A PARTICULAR RECOMMENDATION}

In its 1996/97 annual expert's report, the GCEE proposes a wage policy that is similar though not identical to the one of Proposition 2. This section presents and compares the GCEE's approach to our results.

The GCEE considers the labor demand of competitive, profit-maximizing firms. It starts from the fact that for the constant-returns-to-scale production function, $F(K, A L)$, the marginal product of labor, $M P L(t)$ can be written as the product of labor productivity and the labor share

$M P L(t) \equiv \frac{Y(t)}{L(t)}[1-\alpha(t)]$

It follows that

$g_{M P L}(t)=\alpha(t) g_{K}(t)+[1-\alpha(t)] g_{A}(t)-\alpha(t) g_{L}(t)-\frac{\dot{\alpha}(t)}{1-\alpha(t)}$,

where the first three terms represent the growth rate of labour productivity and the last term is the growth rate of the labour share.

\footnotetext{
${ }^{2}$ The chosen value for $\alpha$ is the average share of capital in a sample of 53 countries analyzed in [12].
} 
The GCEE's recommendation is based on the idea that the observed value of $g_{M P L}(t)$ is likely to be a poor indicator for a wage policy. For instance, if $g_{L}(t)<0$ then $g_{M P L}(t)$ is too high since it includes the productivity gain associated with a decline in the level of employment, an artefact of the concavity of the underlying production function. Hence, the recommended wage policy, $g_{w}^{G C E E}(t)$, eliminates this effect, i.e., $\alpha(t) g_{L}(t)$ disappears in (22) and

$g_{w}^{G C E E}(t) \equiv \alpha(t) g_{K}(t)+[1-\alpha(t)] g_{A}(t)-\frac{\dot{\alpha}(t)}{1-\alpha(t)}$,

The comparison with $g_{w}^{P}(t)$ of Proposition 2 gives the following result.

Proposition 3 It holds that

$$
\begin{aligned}
& g_{w}^{P}(t)-g_{w}^{G C E E}(t)=-\left[g_{\tau_{g}} \frac{\tau_{g}(t)}{1+\tau_{g}(t)}+g_{\mu}(t)\right] \\
& -\frac{\alpha(t)}{\sigma(t)} g_{N}(t)-\alpha(t) g_{L}(t)\left(1-\frac{1}{\sigma(t)}\right) .
\end{aligned}
$$

Proof Straightforward manipulations reveal that

$$
\begin{aligned}
& \frac{\dot{\alpha}(t)}{1-\alpha(t)}=g_{k}(t) \alpha(t)\left(1-\frac{1}{\sigma(t)}\right)= \\
& =\left[g_{K}(t)-g_{A}(t)-g_{L}(t)\right] \alpha(t)\left(1-\frac{1}{\sigma(t)}\right)
\end{aligned}
$$

Using the latter in (23), we have

$$
\begin{aligned}
& g_{w}^{G C E E}(t)=g_{A}(t)+\alpha(t) g_{L}(t)+\left[g_{K}(t)-g_{A}(t)-g_{L}(t)\right] \frac{\alpha(t)}{\sigma(t)} \\
& =g_{A}(t)+\left[g_{K}(t)-g_{A}(t)\right] \frac{\alpha(t)}{\sigma(t)}+\alpha(t) g_{L}(t)\left(1-\frac{1}{\sigma(t)}\right) .
\end{aligned}
$$

In view of the result of Proposition 2, Proposition 3 is immediate.

Proposition 3 points to three differences. Obviously, $g_{w}^{P}(t)$ tends to be smaller than $g_{w}^{G C E E}(t)$ if $\tau_{g}$ and/or firms' market power increases. Second, $g_{w}^{P}(t)$ accounts for changes in the supply of labour. The third difference occurs because $g_{w}^{G C E E}(t)$ does not eliminate the effect of $g_{L}(t)$ on the evolution of the labour share. From equation (25) in the proof of Proposition 3 it is obvious that this omission biases the value of $g_{w}^{G C E E}(t)$ upward if $g_{L}(t)<0$ and $\sigma(t)>1$ or if $g_{L}(t)>0$ and $\sigma(t)<1$.

Proposition 4 Consider the case where $d \tau=g_{\mu}(t)=g_{N}(t)$ $=0$. Then,

$g_{w}^{P}(t)=g_{w}^{M P L}(t)+g_{L}(t) \frac{\alpha(t)}{\sigma(t)}$.

Proof The proposition follows from (16), (22), and (24) in conjunction with $d \tau=g_{\mu}(t)=g_{N}(t)=0$
Proposition 4 shows that the neutral wage policy, $g_{w}^{P}(t)$, obtains from $g_{w}^{M P L}(t)$ if the term $g_{L}(t) \alpha(t) / \sigma(t)$ is added. Intuitively, this procedure eliminates the two effects of $g_{L}(t)$ on the right-hand side of (22). The first effect is on labor productivity $Y(t) / L(t)$, the second is on the labor share 1- $\alpha(t)$. Moreover, $g_{w}^{G C E E}(t)$ neutralizes the first effect but not the second. If $\sigma(t)=1$ then $\dot{\alpha}(t)=0$ and the second effect has no bite. Then under the conditions of Proposition $4 g_{w}^{P}(t)=$ $g_{w}^{G C E E}(t)$.

\section{CONCLUDING REMARKS}

This paper derives a benchmark, the neutral wage policy, that allows to assess whether the actual evolution of the real wage contributes to a reduction in the unemployment rate or not. This benchmark states the growth rate of the real wage that is consistent with a constant unemployment rate. It is derived from an extended neoclassical framework and depends both on changes on the supply and the demand side of firms.

In a steady state, the neutral wage policy would coincide with the growth rate of labor-saving technical change. Outside of a steady state, changes that render product markets more competitive tend to raise the neutral wage policy. Similarly lower consumption taxes or reductions in the non-wage labour costs are found to augment the neutral wage policy. Finally, capital growth in excess of the growth rate of technical change and the growth rate of the labour supply allows for a higher neutral wage policy. Some but not all of these factors show up in the concept of an employment-neutral wage policy of the GCEE [1]. However, the latter can be shown to be a special case of the neutral wage policy.

The calibration exercise of Section IV suggests that in the chosen analytical framework wage moderation can have considerable effects on the unemployment rate. However, besides the caveat that these calibrations hinge on the assumption of a Cobb-Douglas production function, one should keep in mind that our results are derived in a closed economy. Future research ought to focus on wage policies in open economies. Phenomena like capital mobility, migration of workers, or changes in the terms of trade are likely to affect the evolution of domestic wages that is consistent with a given rate of unemployment.

\section{ACKNOWLEDGEMENT}

Financial assistance from Deutsche Forschungsgemeinschaft under the scholarship IR44 $1 / 1$ is gratefully acknowledged.

\section{REFERENCES}

Sachverständigenrat. Jahresgutachten 1996/97 - Reformen voranbringen. Metzler-Poeschel, Stuttgart, 1996.

Blanchard OJ, Giavazzi F. Macroeconomic effects of regulation and deregulation in goods and labor markets. Q J Econ 2003; 118:879-907.

Branson WH. Macroeconomic theory and policy. $3^{\text {rd }}$ ed. AddisonWesley Pub Co: Boston 1989.

Dabricki JZ, Takayama A. Minimum wage regulation and economic growth. J Econ Bus 1982; 34: 231-40. 
[5] Hellwig M, Irmen A. Wage growth, productivity growth, and the evolution of employment. Center for Economic Policy Research (CEPR), Discussion Paper, No. 2927, 2001.

[6] Corneo G, Marquardt M. Public pensions, unemployment insurance, and growth. J Public Econ 2000; 75: 293-311.

[7] Acemoglu D. Labor- and capital-augmenting technical change. J Eur Econ Assoc 2003; 1(1): 1-37.

[8] Barro RJ, Sala-í-Martin X. Economic growth. $2^{\text {nd }}$ ed. MIT Press: Cambridge, MA 2004.

[9] Gregory N. Mankiw, The growth of nations, Brookings Papers on Economic Activity 1995; 1: 275-326.
[10] Ventura J. Growth and interdependence. Q J Econ 1997; 112(1): 57-84.

[11] Klump R, McAdam P, Willman A. Factor substitution and factor augmenting technical progress in the US: a normalized supply-side system approach. Rev Econ Stat 2007; 89(1): 183-92.

[12] Bernanke BS, Gürkaynak RS. Is growth exogenous? Taking Mankiw, Romer, and Weil seriously. In: Bernanke BS, Rogoff KS, Eds. NBER Macroeconomics Annual 2001. MIT Press: Cambridge, MA 2001.

(C) Andreas Irmen; Licensee Bentham Open.

This is an open access article licensed under the terms of the Creative Commons Attribution Non-Commercial License (http://creativecommons.org/licenses/by$\mathrm{nc} / 3.0 /$ ) which permits unrestricted, non-commercial use, distribution and reproduction in any medium, provided the work is properly cited. 